\title{
Availability Assessment of Groundnut and Beans Residue Using Remote Sensing and GIS-A Case Study of Bogoro Local Government Area, Bauchi State, Nigeria
}

\section{Kyauta EE*, Bello AA, Habou D and Ejilah RI}

Department of Mechanical/Production Engineering, Abubakar Tafawa Balewa University, Bauchi, Nigeria

"Corresponding author: Kyauta EE, Department of Mechanical/Production Engineering, Abubakar Tafawa Balewa University, Bauchi, Nigeria, Tel: 08132457140; Email: kyauta8@gmail.com

Rec date: August 23, 2018; Acc date: September 17, 2018; Pub date: September 19, 2018

Copyright: (C) 2018 Kyauta EE, et al. This is an open-access article distributed under the terms of the Creative Commons Attribution License, which permits unrestricted use, distribution, and reproduction in any medium, provided the original author and source are credited.

\section{Abstract}

The demand for energy especially in small scale applications is increasing day by day worldwide. The major quantum of energy demand is met through fossil fuels. The associated greenhouse gas (GHG) emission has been of serious global environmental concern. This has made it necessary for future projected energy demand to come from renewable energy sources in other to reduce GHGs emission to an acceptable level. Globally, crop residue biomass has been acknowledged as a positive alternative source of energy because it is renewable, cheaper, readily available and carbon neutral. In this study a geographic information system (GIS) and remote sensing (RS) based methodology was developed to assess the availability of groundnut shell and beans husks in Bogoro Local government area. The analysis gave a total residue estimate in the study area to be $133,687.68$ tonnes and $215,725.8$ tonnes for beans husks and groundnut shell respectively. Out of the 10 wards considered Boi $B$ ward has the highest residue of 33,639.8 tonnes followed by Lusa A ward with 31,986 tonnes for groundnut. While for Beans, Lusa A has the highest value of $16,572.92$ followed by Bogoro B with $15,582.28$ tonnes. This information is important to the successful utilization of these residues.
\end{abstract}

Keywords: Crop residue; Remote sensing; Crop yield; Geographical information system

\section{Introduction}

The demand for energy especially in small scale applications is increasing day by day worldwide. It is also projected that per capita energy demand (toe) globally would increase from 1.8 in 2007 to 2.0 in 2030 [1]. The major quantum of energy demand is met through fossil fuels, but the associated greenhouse gas (GHG) emission from burning of fossil fuel has been the top global environmental concern. Other problems like diminishing fuel reserves, precarious oil markets, population growth in major parts of the globe seems to force almost all the nations to search for renewable energy for future energy security. Thus, significant share of future energy has to come from renewable energy sources to meet the projected demand and to reduce GHGs emission to an acceptable level. Globally, biomass has been acknowledged as a positive alternative source of energy because it is renewable, cheaper, readily available and carbon neutral. Unlike other renewable energy sources such as solar and wind, biomass can be converted into various fuel forms (liquid, solid and gas) through many biomass conversion technologies. Several biomass technologies have been mentioned as being viable for energy generation through direct combustion, gasification, briquetting, biogas and many more [2]. However, the use of biomass resources in developing countries is mostly limited to cooking, heating and lighting [3].

In Nigeria agricultural land constitutes approximately $74,500,000$ ha of the total land area of $91,077,000$ ha for the country. About $41.2 \%$ of the agricultural land is arable land, Nigerian population are involved in agricultural production with more than $70 \%$ of the farming population being smallholder farmers ( $<5 \mathrm{ha})$ (CIA, 2012). This high percentage arable land is a potential for high crop residue generation. Unfortunately, only national level estimate of crop residue biomass potential in Nigeria is available with limited data base on state and local level. Since bioenergy projects are generally of small scale and targeted mainly for decentralized utilization to meet local energy demand, national estimates may not be adequate for state or local bioenergy planning. The first step in setting up any biomass based plant is to identify and estimate relevant biomasses available in specific areas and regions. Hence the estimation of spatial distribution of economically exploitable crop residue is the backbone for a successful renewable energy potential and ultimately instrumental in the designing of agro waste bioenergy power plants with sustainable supply of crop residue. The bulky nature or low energy density of agricultural residues possesses some challenges in handling, storage, transportation and conversion processes. Therefore, it becomes necessary to ensure availability of adequate crop residue in the vicinity of Potential of biomass plant location. In identifying this gap, we used Remote Sensing (RS) and Geographical Information System (GIS) tools to investigate the crop residue availability in the study area.

\section{Review of Literature}

In order to assess the availability and geographical distribution of crop residues, it is necessary to review research in the area of crop residue use for energy generation. Nigeria is blessed with an abundant mix of renewable energy sources such as biomass, solar, wind and hydro-power, among these options, biomass stands higher because it is uniformly spread in the country. Biomass based energy has a vital role in the rural life where agriculture is the principal activity [4]. The use of biomass as a source of energy has the advantages of being readily available and can be used without essential damage to the 
Citation: Kyauta EE, Bello AA, Habou D, Ejilah RI (2018) Availability Assessment of Groundnut and Beans Residue Using Remote Sensing and GIS-A Case Study of Bogoro Local Government Area, Bauchi State, Nigeria. J Remote Sens GIS 7: 249. doi: $10.4172 / 2469-4134.1000249$

Page 2 of 5

environment. In addition, biomass resources are considered renewable as they are naturally occurring by comparison with other renewable energy resources such as solar and wind. It is a storable resource, inexpensive and has favorable energetic efficiency. Crop residue resources available in the study area include: agricultural crops residues, such as groundnut shell, maize cobs rice husk, sorghum and beans husk [5].

According to Simonyan and Fasina [6] there are great opportunities for exploitation of different types of biomass in Nigeria with an estimated 2.01 EJ (47.97 MTOE). But the use of bioenergy has not been given serious implementation attention in Nigeria. The energy challenge of Nigeria will be a thing of the past if the abundant biomass resources in the country are tapped. A key challenge for biomass based energy production is to ensure that the right kind, the right quality, the right amount and the right channels of procurement of biomass are available within a certain distance from the plant. Each of the above is essential for the effective and economic operation of the biomass based plants.

The first point to note is that different types of biomass plants (gasifiers) require different kinds of biomass. Consequently, the location of gasifiers has to be in line with the kind of biomass available in that location. Secondly, the right quality of biomass is necessary in order to increase the efficiency of these plants. Thirdly, the right amount of biomass is the one that matches to the requirement of the power plant. For instance, a $30 \mathrm{~kW}$ gasifier running for 10 hours daily for 350 days a year requires $210 \mathrm{MT}$ of biomass annually. In contrast, a 1000 Kilowatt requires 7000 MT of biomass. The channels of procurement of biomass are the ones that reduce the cost of running of biomass based power plants. From the above it becomes clear that the first step in setting up any biomass plant is to identify and estimate relevant biomass resource available in specific areas and regions.

According to Abdullah et al. [7] to safeguard the nation's energy security and ensure clean, renewable and sustainable energy supplies the current fossil fuel energy systems will need to be integrated with bioenergy generation in future hybrid systems. One of the research gaps for bioenergy industries in Nigeria as reported by Sambo [8] is inadequate resource assessment and reliable resource database to assist investment decisions for renewable energy utilization. Agbro and Ogei [9] also reported that there is hardly any detailed documentation on the various biomass resources available in literature.

\section{Crop residue biomass utilization}

Biomass is a collective term used for all materials that are biogenic in origin that is, derived from the product of photosynthesis Kishor. Biomass can be of various types; it can have plant or animal-origin. Biomass in the form of fuelwood was perhaps the first energy source used by human beings and was the main fuel till the industrial revolution, after which fossil fuels like coal and oil replaced biomass as the main fuels.

In Nigeria, crop residues are significant sources of biomass because agricultural sector is a major contributor to the nation's economy. According to Sambo [5], biomass resources estimate in Nigeria shows the quantity of agricultural waste to be 11.2 million tonnes with an energy value of $147,700 \mathrm{MJ}$.

The production data of top 10 agricultural crops in Nigeria is reported in Table 1 (Cassava, Cowpea, Groundnuts, Maize, Millet, Plantains, Oil Palm, Rice, Sorghum and Soybeans) [10]. Reports by United Nations Food and Agricultural Organization (FAOSTAT, 2012) and NASS (2012) [11] indicated that crop residues do not usually appear in official statistics hence an estimate of the amount of crop residues produced were made based on crop production.

Diyoke et al. [12] recommended that an accurate estimate of the potential biomass resource base in Nigeria should be undertaken for implementation of a decentralized biomass gasification power plant. According to Simonyan and Fasina [6], some researchers combined the production data with the residue- to- product ratios (RPR) of the different crops to obtain the amount of residues for each annual crop [11]. Jekayinka and Scholz [13] also adopted the following procedure for crop residues estimation in Nigeria:

- A known quantities of crop production multiplied with residue to product ratio (RPR) to estimate the amounts of agricultural residues.

- The energy values of the available crop residues are computed by multiplying the known heating values $(\mathrm{MJ} / \mathrm{kg})$ of the residues by their estimated weight.

The estimated crop land crop productions data of major crops in Bogoro local government area is as shown in Table 1. The results showed that 30,811 ha is the total land cultivated with a total production value of 45,357 metric tons.

The results indicate that the average total amount of residues generated in Nigeria is 73.30 million tonnes. A total of 1.81 million tonnes of groundnut shells was generated with a corresponding energy value of 28.35 PJ by Bhattacharya. While beans have 9.77 million tonnes of husks with energy value of 95.06 PJ [13]. The data of the crops growing in an area considers how much land area is being covered by these crops. The information about grain productivity and the ratio of grain to straw is taken from secondary approach such as research papers or by conducting a primary study in the location.

\begin{tabular}{|l|l|l|l|}
\hline Crop & $\begin{array}{l}\text { Cultivated } \\
\text { Area }(\mathbf{H a})\end{array}$ & $\begin{array}{l}\text { Crop Production } \\
\text { (metric tonnes) }\end{array}$ & $\begin{array}{l}\text { Yield } \\
\text { (metric tonnes/ha) }\end{array}$ \\
\hline Sorghum & 6,821 & 12,746 & 1.87 \\
\hline Maize & 6,661 & 10,596 & 1.6 \\
\hline Groundnut & 4,391 & 7,983 & 1.82 \\
\hline Rice & 4,459 & 7,993 & 1.79 \\
\hline Beans & 3,301 & 1,771 & 0.86 \\
\hline Acha & 4,947 & 4,266 & 0.86 \\
\hline Total & $\mathbf{3 0 , 5 8 1}$ & $\mathbf{4 5 , 3 5 7}$ & \\
\hline
\end{tabular}

Table 1: Crop production estimate for Bogoro local government area in 2016. Source BSADP 2016.

\section{Methodology}

The methodological aspect of this research is grouped into three; first is the field survey and ground data collection, the second aspect is the data preparation and other remote sensing analysis. Prior to mapping of groundnut and beans croplands of the study area, handheld GPS (Garmin GPS72H) was used to collect ground control points (GCPs) of randomly selected locations of the study area. The GCPs were then compared with the satellite image to ascertain whether spectral signature of a particular feature present in the image 
Citation: Kyauta EE, Bello AA, Habou D, Ejilah RI (2018) Availability Assessment of Groundnut and Beans Residue Using Remote Sensing and GIS-A Case Study of Bogoro Local Government Area, Bauchi State, Nigeria. J Remote Sens GIS 7: 249. doi: $10.4172 / 2469-4134.1000249$

Page 3 of 5

matches with ground reality. The points were used for verification and validation of the remote sensing analysis in image classification and crop identification. The field survey was carried out in August 2017. A total of 215 farms were visited, of which 162 points were groundnuts farms while 52 points were beans [11].

\section{Remote sensing analysis and data preparation}

The images dated 17th September 2017 were already orthorectified before acquisition. This is with the assumption that the crops under study (beans and groundnuts) will be at their spectral peak at that period and thereby making the Normalized Differential Vegetation Index (NDVI) analysis more reliable. The downloaded Landsat image contains 11 multispectral bands, consisting of bands useful for optical, microwave and thermal remote sensing analysis was used for both NDVI and Landuse/Landcover (LULC) analysis. The first step involves the unification of all data to the same projected zone (Projected Northern Hemisphere - Universal Transverse Mercator (UTM) - Zone 32). In the second analysis all layers were subset to the spatial extent of the study area (Bogoro LGA). This was achieved by using the LGA boundary shape file of the study area in the Analyst tools function of ArcGIS 10.3. The third analysis here was layer stacking as three optimal bands were selected from the 11 downloaded Landsat bands. Bands 5, 4 and 3 were selected and stacked as "Green", "Red", and "Blue" bands. This was stacked to form one 'false color composite" image which is appropriate for Land use/Land cover (LULC), based on the desired LULC classes.

A supervised image classification was used for generating the LULC map of the study area using the Erdas Imagine 9.2 Package. Training sites or training pixels were created on the satellite images for each land cover type and the grouped pixels were coded accordingly to represent a LULC class. Using the sampled signatures generated for these classes, the maximum likelihood method classifies the entire image. The LULC table was exported to Excel to calculate the total coverage of each class in hectare (ha) and percentage (Figure 1).

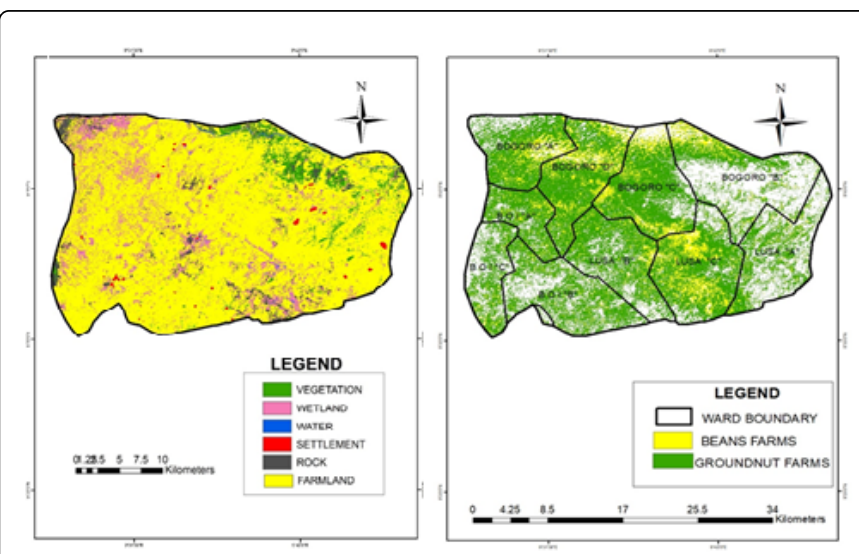

Figure 1: 2017 Landuse/Landcover of Bogoro LGA.

\section{Identification of groundnut and beans farms}

Normalized Differential Vegetation Index (NDVI) was generated using the respective spectral channels that is, Near Infra-Red (NIR) and visible Red and the corresponding bands in the wavelengths of Landsat ETM+platform. The bands 5 and 4 were selected for NIR and
Red respectively. The purpose of this analysis here is to determine the spectral signatures of farms especially groundnut and beans.

The NDVI universal equation is shown below:

$$
N D V I=\frac{N I R-V I S I B L E}{N I R+V I S I B L E}
$$

Here the NDVI was crossed with the farms points collected on the field, this is to ascertain the NDVI reflectance and spectral signature values for beans and groundnuts. This analysis was performed using the "Extract Values to Point" tool in ArcGIS using the NDVI and field points as inputs. Once the spatial location of the crops (groundnut and beans) was established and extracted, the area covered for each was calculated using the geometry analyst in ArcGIS 10.3. The area was calculated in hectares for each crop type using the total pixel counts multiplied by the pixel value of the Landsat data $\left(30 \times 30=900 \mathrm{~m}^{2}\right)$. The area of each crop was then multiplied by the value of yield per hectare of the study as obtained from Bauchi state agricultural development Project office. The total crop production yield was then multiplied by the residue product ratio of each crop to generate the residue in the study area [13].

\section{Results}

To test the accuracy and validate the classification procedure, the farmlands were selected separately and cross-checked with the farm points collected on the field. A total of 215 farms were visited and the results of validations of the field points shows that a total of 205 points out of 215 farm points fall within the farm class indicating an accuracy of $95 \%$ and the remaining 10 points fell within wetland and water.

\section{Analysis of land use and land cover}

The results of image classification show the land use and Land cover of the study area on visual map in Figure 2 and an accompanying statistical table (Hectograph) Figure 3. The map shows the classes generated as follows: Farmlands, Vegetation, Water, Rock and Wetland. Farmland has the highest coverage with a value of $69,667.74$ ha which is $78.29 \%$ of the total land cover.

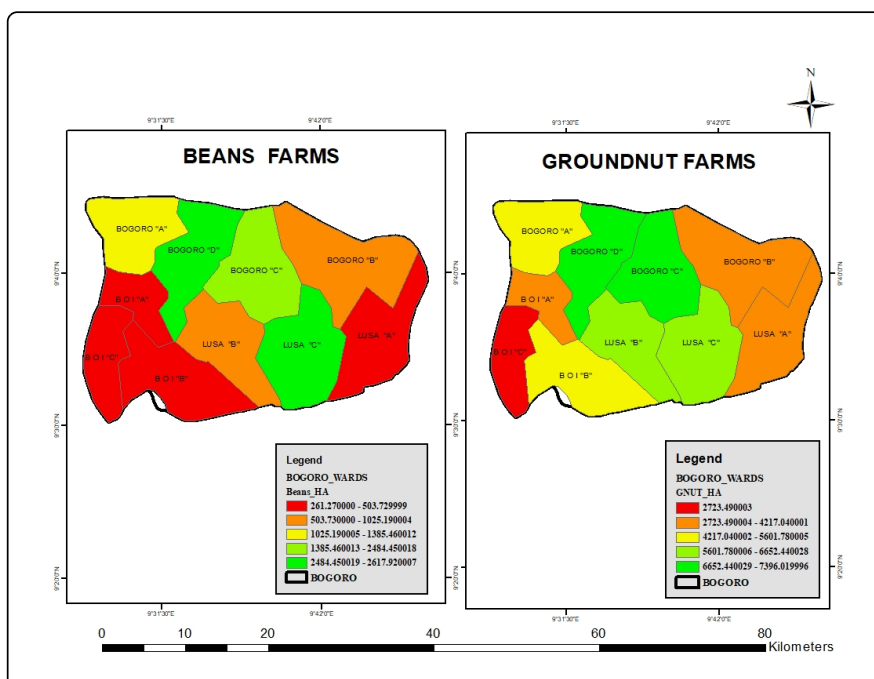

Figure 2: Estimated Beans and groundnut farm. 
Citation: Kyauta EE, Bello AA, Habou D, Ejilah RI (2018) Availability Assessment of Groundnut and Beans Residue Using Remote Sensing and GIS-A Case Study of Bogoro Local Government Area, Bauchi State, Nigeria. J Remote Sens GIS 7: 249. doi: $10.4172 / 2469-4134.1000249$

Page 4 of 5

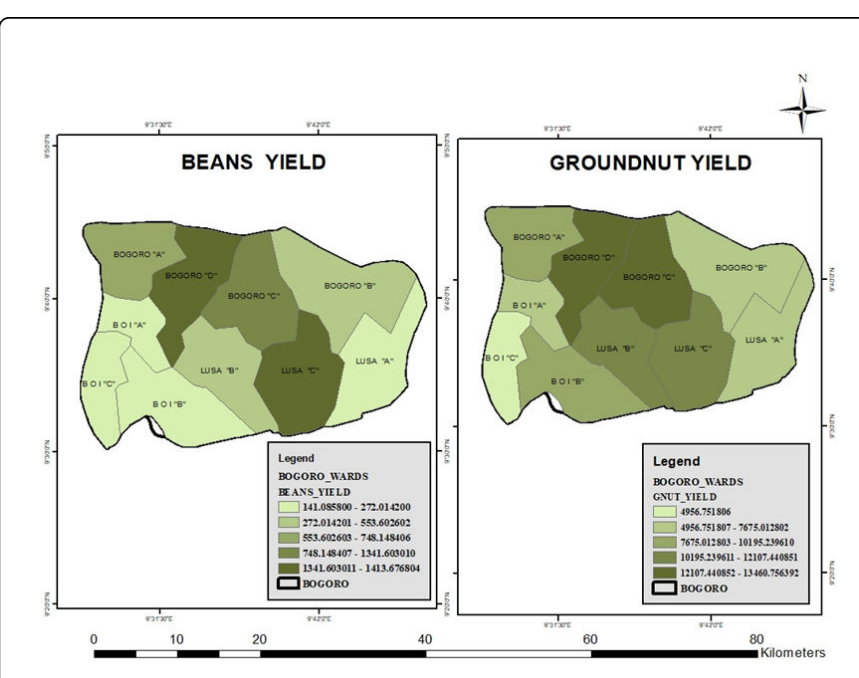

Figure 3: Groundnut and Beans yield bases on ward.

\section{Calculations of groundnut and beans farms}

This analysis was performed using the "Extract Values to Point" tool in ArcGIS using the NDVI and field points. The inputs revealed that the NDVI values of the groundnut farms is within the range of 0.21 to 0.46 as shown in Figure 4. Similar case applies for the beans farms, as the beans farms ranges between 0.20 to 0.38 .

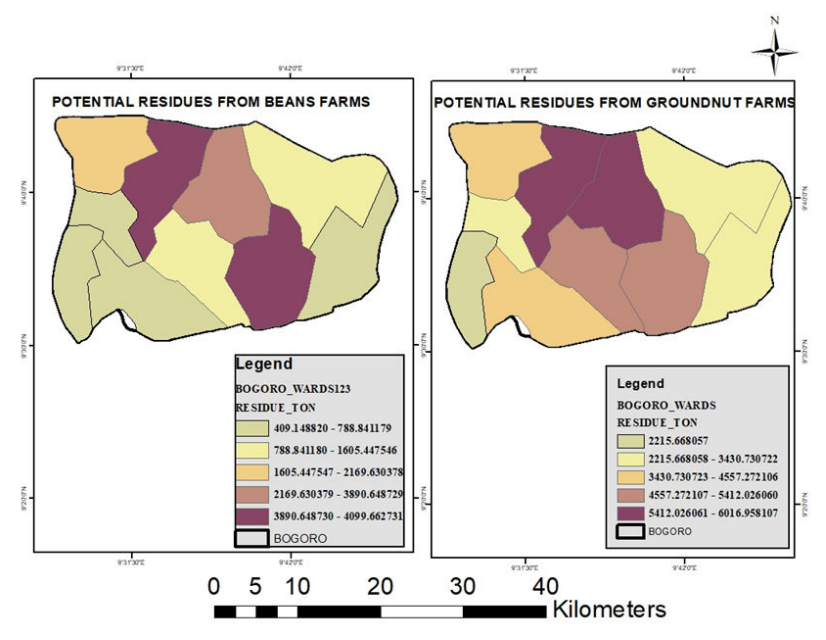

Figure 4: Groundnut and Beans Residue generated based onwards.

\section{Discussion of Results}

This study estimated the amount of crop residues in Bogoro local government area utilising a GIS based approach. For each of the wards crop residues were assessed at village level. The residues estimated were groundnut shells and beans husks. In addition, a GIS tool that automates the process of crop residue estimation was created using ArcGIS extension Model Builder. To test the accuracy and validate the classification procedure, the farmlands were selected separately and cross-checked with the farm points collected on the field. A total of 215 farms were visited and the results of validations of the field points shows that a total of 205 points out of 215 farm points fall within the farm class indicating an accuracy of $95 \%$ which is very adequate for the analysis.

The image classification revealed that farmland has the highest coverage with a value of $69,667.74$ ha which is $78.29 \%$ of the total land cover. The total amount of crop residue for the two crops selected in the study area is about $385,413.48$ tonnes. The results showed the amount per crop to be $215,725.8$ and $133,687.68$ tonnes for groundnut shells and beans husks respectively. The result is higher than that of Ibrahim where it was reported that the estimate of groundnut shells generated for Bauchi state in 2014 was 144,352 tonnes. This high difference may be due the assessment method or the difference in land use within the years. The groundnut shell has a higher crop residue generated because it was found to be the dominant crop in that planting season.

The results of crop residue at national level as reported by Jekayinka and Scholz [13] gave the value of beans husks to be 9.7 million tonnes while a study by Bhattacharya revealed 1.81 millions tonnes of groundnut shells. The high results may be due to high agricultural productions which is consistent with other studies where regions with high agricultural production resulted in higher residue yields [14]. In addition, this study presents a GIS tool that automates the process of estimating the crop residues at village level in Bogoro. This model is an automated process of estimating the theoretical amount of crop residue biomass, this model created for Bogoro can be transferable to other local governments

\section{Conclusion}

The following could be concluded from the study of remote sensing and GIS. The total residue of 385,413.48 tonnes shows that the use of the crop residue for Potential of biomass can be sustained. The precise information on biomass resource strength will contribute in decision making process for policy makers on biomass energy development.

The GIS model developed will enhance the assessment of agricultural residue in the study area and other location there by reducing the burden of using traditional means of assessment.

\section{References}

1. IEA (2012) Energy balance for Nigeria. OECD/IEA.

2. Nzila C, Dewulf J, Spanjers H, Kiriamiti H, van Langenhove H (2010) Biowaste energy potential in Kenya. Renewable Energy 35: 2698-2704.

3. Janssen R, Rutz D (2011) Bioenergy for sustainable development in Africa. Springer Science \& Business Media, Germany.

4. Ramchandra TV, Joshi NV, Subramsnian DK (2000) Present and prospective role of bioenergy in regional energy system. Renew Sust Energy Rev 4: 375-430.

5. Sambo AS (2009) Strategic Developments in Renewable Energy in Nigeria. International Association for Energy Economics, Pp: 15-19.

6. Simonyan JJ, Fasina O (2013) Biomass resource and Biofuel Potential in Nigeria. African Journal of Agricultural Research 8: 4975-4989.

7. Abdullai MM, Achoba MI, Kawuwa SA (2015) Role of Biomass Energy Technologies in Ensuring Energy Security in Nigeria. Journal of Multidisciplinary Engineering Science and Technology 2: 2576-2580.

8. Sambo AS (2006) Renewable energy electricity in Nigeria: The way forward. Paper presented at the Renewable Electricity Policy Conference held at Shehu Musa Yarádua Centre, Abuja, pp: 11-12. 
Citation: Kyauta EE, Bello AA, Habou D, Ejilah RI (2018) Availability Assessment of Groundnut and Beans Residue Using Remote Sensing and GIS-A Case Study of Bogoro Local Government Area, Bauchi State, Nigeria. J Remote Sens GIS 7: 249. doi: $10.4172 / 2469-4134.1000249$

Page 5 of 5

9. Agbro EB, Ogie NA (2012) A comprehensive review of biomass resources and biofuel production potential in Nigeria. Research Journal in Engineering and Applied Sciences 1: 149-155.

10. FAO (2013) Agricultural Database.

11. NASS (2012) Collaborative survey on national agricultural sample survey 2010/2011. National Bureau of Statistics and Federal Ministry of Agriculture and Rural Development.

12. Diyoke C, Idogwu S, Ngwaks UC (2014) An Economic Assessment of Biomass Gasification For Rural Electrification In Nigeria. International Journal of Renewable Energy Technology Research 3: 1-17.
13. Jakayinka SO, Scolz V (2007) Assessment of availability of cost energetically usable crop residues in Nigeria. Conference on International Agricultural Research for Development. University of Kassel, Germany.

14. Scarlat N, Martinov M, Dallemand JF (2010) Assessment of the availability of agricultural crop residues in the European Union: potential and limitations for bioenergy use. Waste Management 30: 1889-1897. 